Research, part of a Special Feature on Urban Sprawl

\title{
Elevated Levels of Herbivory in Urban Landscapes: Are Declines in Tree Health More Than an Edge Effect?
}

\author{
$\underline{\text { Fiona J. Christie }}^{1}$ and Dieter F. Hochuli ${ }^{1}$
}

\begin{abstract}
Urbanization is one of the most extreme and rapidly growing anthropogenic pressures on the natural world. Urban development has led to substantial fragmentation of areas of natural habitat, resulting in significant impacts on biodiversity and disruptions to ecological processes. We investigated the levels of leaf damage caused by invertebrates in a dominant canopy species in urban remnants in a highly fragmented urban landscape in Sydney, Australia, by assessing the frequency and extent of chewing and surface damage of leaves in urban remnants compared to the edges and interiors of continuous areas of vegetation. Although no difference was detected in the frequency of leaves showing signs of damage at small, edge, and interior sites, small sites suffered significantly greater levels of leaf damage than did interior sites. Trees at edge sites showed intermediate levels of damage, suggesting that edge effects alone are not the cause of higher levels of herbivory. These findings are the first to demonstrate the effects of urbanization on invertebrate damage in dominant trees at coarse scales. This is consistent with hypotheses predicting that changes in species composition through urban fragmentation affect ecological interactions.
\end{abstract}

Key Words: urban landscapes; herbivory; invertebrates; urbanization; remnant vegetation; fragmentation; leaf damage; Australia

\section{INTRODUCTION}

Urbanization is one of the most extreme and burgeoning anthropogenic causes of disturbance, resulting in major habitat loss and increased fragmentation of natural vegetation. Habitat fragmentation has been associated with a range of disruptions to ecological processes and changes in all components of biodiversity, with the loss of specific trophic groups having significant effects on system functioning (Banks 1998, Rao et al. 2001, Laurance et al. 2002). In addition to habitat loss, fragmentation leads to significant modification of the environment, including changes to nutrient flows (Pouyat et al. 1995, Evelegh et al. 2001) and fire regimes, and to a susceptibility to invasion by highly competitive nonindigenous species (Suarez et al. 1998, King and Buckney 2002).

Small patches of remnant vegetation may be particularly vulnerable to the effects of fragmentation and disruptions to processes, with a loss of what is perceived as core habitat (Chen et al. 1995, Murcia 1995) and an increase in inferior edge habitat (Møller 1989, Bolger et al. 1997). Increases in edge habitat and a high edge:area ratio can contribute to changes in community composition (Bierregaard et al. 1992, Davies and Margules 1998) and abundance of individuals (Golden and Crist 2000, Major et al. 2003). The hostile matrix surrounding remnant bushland and high levels of anthropogenic disturbance (Marzluff and Ewing 2001) may exacerbate the effects of fragmentation in urban systems.

In Australia, myrtaceous species such as Eucalyptus are the dominate vegetation over much of the continent (Fairley and Moore 1989) and a ubiquitous flora of urban remnants. Eucalypts have been found to show consistently high levels of damage by invertebrate herbivores compared to dominant trees in the Northern Hemisphere (Fox and Morrow 1983, Landsberg and Ohmart 1989), although much of this work has looked at 
commercial plantings rather than dominant endemic flora (Stone 2001). Insect herbivory is strongly correlated with foliar nutrients (Ohmart and Edwards 1991), leaf characteristics (Peeters 2002), predation pressures (Gunnarsson and Hake 1999), and disturbance (Spiller and Agrawal 2003). Many of these characteristics may be so impacted by fragmentation events and urbanization (Port and Thompson 1980, Nuckols and Connor 1995, King and Buckney 2002) that biotic responses may potentially alter ecosystem processes such as leaf herbivory.

This paper describes the effects of urban fragmentation on levels of herbivory on a dominant tree in urban forest remnants. We examined mature trees of Angophora costata in small urban patches of vegetation to see if they were suffering from elevated levels of leaf herbivory compared to trees in larger, continuous patches of vegetation.

\section{MATERIALS AND METHODS}

\section{Study area}

Our study was conducted in remnant vegetation within and around the metropolitan area of Sydney, Australia. The Hawkesbury Sandstone of the Sydney Basin occupies approximately $13,000 \mathrm{~km}^{2}$ (Fairley and Moore 1989) and supports a diverse and unique flora. Sandstone Gully Forest and Ridgetop Woodlands form one of the area's most common remaining vegetative assemblages (Benson and Howell 1990). Despite high levels of urban development, this assemblage persists as small urban reserves within the metropolitan area and is represented in the large national parks that border the city. The dominant canopy species of this community are Angophora costata (smooth-barked apple, family Myrtaceae) and Corymbia gummifera (red bloodwood), whereas the understorey consists of numerous species of Hakea, Acacia, Banksia, and Epacris.

We selected 15 study sites from Sandstone Gully Forest and Ridgetop Woodland forests from the study area (Fig. 1). Five "small" remnants ( $<65$ ha) were chosen from bushland reserves within the urban matrix. Five "interior" sites were selected within large patches of continuous bushland located within national parks to the north and south of Sydney's central business district. These interior sites were all located more than $4 \mathrm{~km}$ from the woodland edge. Another five "edge" sites were located within $100 \mathrm{~m}$ of urban areas at the urban/ woodland edge of large continuous patches of vegetation.

\section{Estimation of leaf damage}

Branches of A. costata were collected in April 2001 over a two-day period. Five trees $8.5-16 \mathrm{~m}$ in height were sampled at each study site. We selected trees that showed no obvious signs of leaf damage or stress and whose canopy leaves could be accessed with a pole pruner with a maximum extension of 11 $\mathrm{m}$. A single sample was clipped from the distal 50 $\mathrm{cm}$ of each of four branches on four compass points around the tree. Samples were then sealed in labeled plastic bags and removed to the laboratory for processing. Twenty-five fully expanded terminal leaves were subsampled from each sample, giving a total of 100 leaves per tree. Dummy numbers were assigned to subsamples so that final assessments of leaf damage could be conducted double blind.

Groups of leaves were placed adaxial side up on a piece of white paper on a light box. Leaves were then flattened with a sheet of glass to eliminate shadows and photographed using a digital camera at a fixed focal length. Leaf damage was categorized as either chewing damage in which part of the lamina was physically missing, such as holes within leaves or incomplete leaf margins, or surface damage, which included all damage that had not physically reduced the extent of the lamina, such as necrosis, mining, skeletonizing, galls, and fungal damage.

Levels of leaf-chewing damage were estimated using the Total Proportion Damaged (TPD) method (Landsberg 1989). Leaf images were imported into a KS400 Image Analysis System, and an automated program was used to obtain a measure of actual leaf area (ALA) for each leaf. Potential leaf area (PLA) was determined by estimating where the leaf would have grown in the absence of herbivory. The missing area and measure of leaf-chewing damage was calculated as the difference between the PLA and the ALA. Total proportion damage (TPD) for chewing damage per leaf was calculated using the following formula: 
Fig. 1. Location of small remnant (diamond), edge (square), and interior (triangle) study sites in the Sydney Basin. The shaded area represents the extent of the large national parks and reserves that border the city to the north and south. Unshaded areas represent urban areas. CBD stands for "central business district."

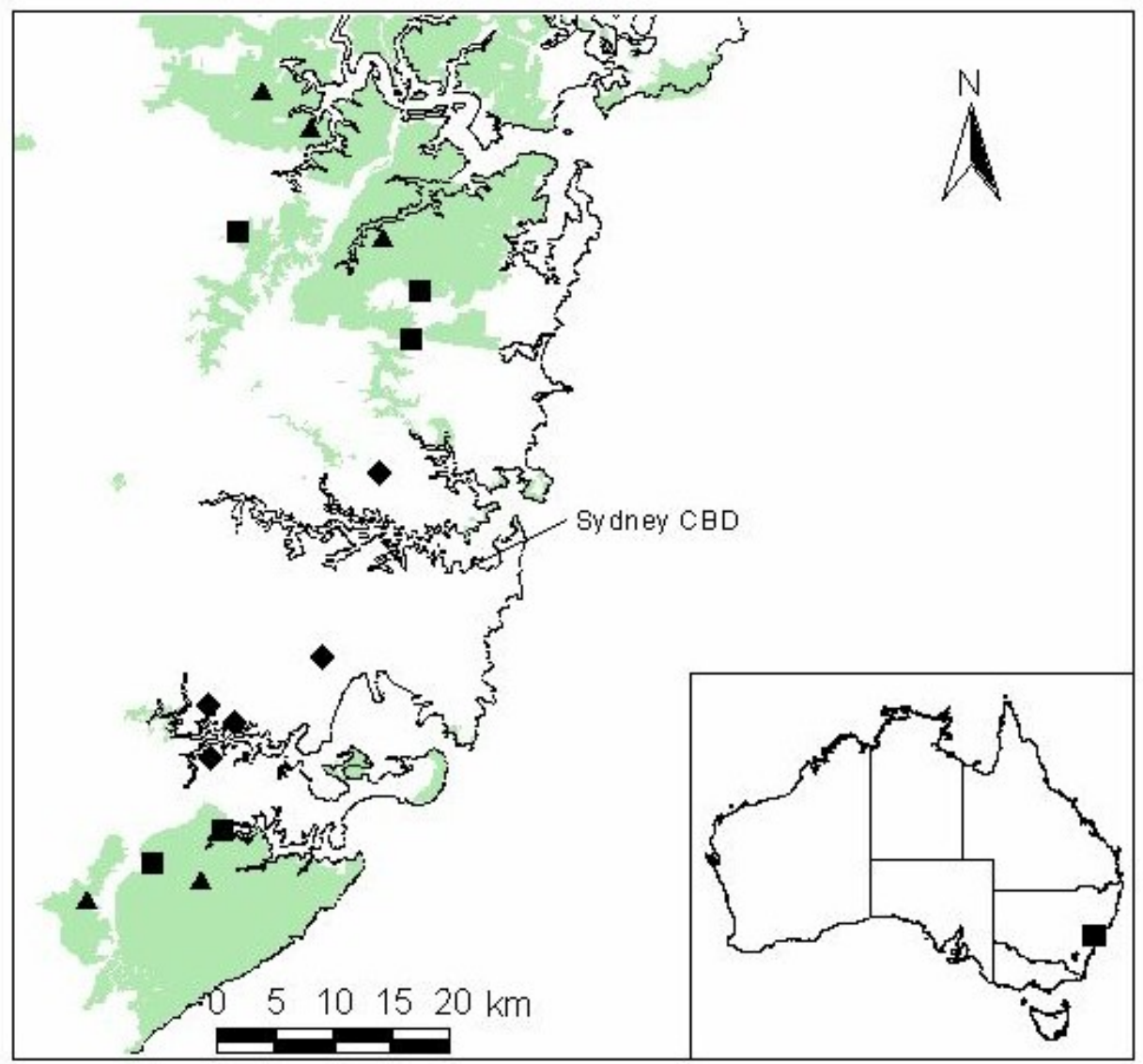

\section{$T P D=\underline{P L A}-A L A \times 100$ PLA}

Level of chewing damage was then categorized as no damage $(0 \%)$, low $(<5 \%)$, medium $(6-20 \%)$, or high $(21-100 \%)$.

Because most leaves had only low levels of surface damage, much of it evident as small specks, estimates of surface damage could not be made using the same technique as for chewing damage. Consequently, the proportion of surface damage was determined by categorizing the level of damage for each leaf as a percentage of PLA. This was done by visually inspecting each leaf from the leaf images and categorizing the damage observed as detailed above.

\section{Statistical analysis}

One-way analysis of variance was used to test for differences in the frequency of chewing or surface damage of leaves. In these analyses, data from five trees were pooled for each site resulting in five replicates for each of small, edge, and interior treatments. One-way ANOVA, with sites nested and trees as replicates, was used to test for differences in the TPD for chewing and the proportion of surface damage between small remnants, edge, and interior 
Table 1. Percentage of leaves showing signs of damage in each category (no damage, low, medium, and high) for both chewing and surface damage in small remnant, edge, and interior sites ( $n=5$ sites/treatment).

\begin{tabular}{|c|c|c|c|c|c|}
\hline \multicolumn{6}{|c|}{ Chewing damage } \\
\hline \multicolumn{6}{|l|}{ Site } \\
\hline & None & $\begin{array}{l}\text { Low }(0- \\
5 \%)\end{array}$ & $\begin{array}{l}\text { Medium } \\
(6-20 \%)\end{array}$ & $\begin{array}{l}\operatorname{High}(21- \\
100 \%)\end{array}$ & Total $(\%)$ \\
\hline $\begin{array}{l}\text { Small re- } \\
\text { mnant }\end{array}$ & 20 & 53 & 19 & 8 & 80 \\
\hline Edge & 21 & 54 & 20 & 5 & 79 \\
\hline Interior & 24 & 58 & 15 & 3 & 76 \\
\hline \multicolumn{6}{|c|}{ Surface damage } \\
\hline \multicolumn{6}{|l|}{ Site } \\
\hline & None & $\begin{array}{l}\text { Low }(0- \\
5 \%)\end{array}$ & $\begin{array}{l}\text { Medium } \\
(6-20 \%)\end{array}$ & $\begin{array}{l}\operatorname{High}(21- \\
100 \%)\end{array}$ & Total $(\%)$ \\
\hline $\begin{array}{l}\text { Small re- } \\
\text { mnant }\end{array}$ & 44 & 51 & 5 & 0 & 56 \\
\hline Edge & 36 & 56 & 7 & 1 & 64 \\
\hline Interior & 39 & 54 & 6 & 1 & 61 \\
\hline
\end{tabular}

sites on arcsine transformed data. Tukey-Kramer HSD (honestly significant difference) tests were used to determine the source of any differences observed.

\section{RESULTS}

We found chewing damage in $87 \%$ of the leaves collected, whereas $60 \%$ showed signs of surface damage. Frequency of damage was consistent across small remnants, edge, and interior sites (Table 1), with no difference being detected for either chewing $\left(F_{212}=1.19 ; P=0.34\right)$ or surface damage $\left(F_{2,12}=0.57 ; P=0.58\right)$.

Most surface damage was at low levels $(<5 \%)$, with very low frequencies of leaf damage at levels greater than 20\% (Table 1). Most leaves for all site treatments for both surface and chewing damage fell into the low damage category (approximately 50\% of leaves), with a low frequency of leaves showing signs of high levels of damage (Table 1).

The total proportion damage for chewing (Fig. 2) was significantly different (Table 2) between small remnant, edge, and interior sites. Trees in small remnants suffered twice as much leaf damage as did trees in interior sites, whereas trees in edge sites showed intermediate levels of chewing damage. The proportion of surface damage at small remnant, edge, and interior sites was not different (Table 2).

\section{DISCUSSION}

Mature individuals of Angophora costata in remnant bushland in highly urbanized areas suffer from significantly higher levels of leaf damage than do trees in larger continuous patches of vegetation, with trees in edge sites showing intermediate levels of damage. Our results support theories that trees in urban areas suffer from higher levels of chewing damage than those individuals of the same species in larger continuous areas of forest (Port and 
Table 2. Nested analysis of variance for the total proportion of damage (TPD) caused by chewing damage and the proportion of surface damage sustained by Angophora costata in small remnant, edge, and interior sites $(n=15, *$ denotes significance at $P<0.05)$.

\begin{tabular}{|c|c|c|c|c|}
\hline \multicolumn{5}{|c|}{ TPD chewing damage } \\
\hline & $\overline{\mathrm{DF}}$ & SS & $F$ ratio & Prob $>F$ \\
\hline Treatment & 2 & 0.0127 & 9.1807 & $<0.0038^{*}$ \\
\hline Site & 12 & 0.0083 & 1.5318 & 0.1381 \\
\hline Error & 60 & 0.0272 & & \\
\hline \multicolumn{5}{|c|}{ Proportion surface damage } \\
\hline & $\mathrm{DF}$ & SS & $F$ ratio & Prob $>F$ \\
\hline Treatment & 2 & 0.1928 & 0.83 & 0.456 \\
\hline Site & 12 & 1.3793 & 1.8669 & 0.0573 \\
\hline Error & 60 & 3.6943 & & \\
\hline
\end{tabular}

Thompson 1980, De Bruyn et al. 2002) and are more susceptible to outbreaks of defoliating insects (White 1969, Louda and Collinge 1992). However, this response was consistent only for chewing damage, with trends in surface damage less apparent. The highly modified environment of urban remnants may predispose dominant trees in urban remnants to high levels of leaf damage.

The soils of the Hawkesbury Sandstone are characteristically nutrient poor, with native flora well adapted to these conditions (Benson and Howell 1990, King and Buckney 2002). Nutrient enrichment from the surrounding urban environment through sewerage overflows, pet excrement, and runoff from garden fertilizers has significantly altered the soil chemistry of urban remnants in Sydney, leading to increases in nitrogen and phosphorous (King and Buckney 2002). These increased levels of soil nutrients reduce the competitive abilities of native flora and facilitate invasion by nonindigenous flora (King and Buckney 2002). The resulting increase in soil and consequently foliar nutrients may be positively influencing the population dynamics of herbivorous insects in our small urban remnants. Foliar nutrients in roadside and remnant vegetation have been found to be greatly enhanced through enrichment from anthropogenic activities (Port and Thompson
1980). Available nitrogen is one of the potentially limiting factors to the performance and survival of invertebrate herbivores (White 1984, Hanks and Denno 1993, Peeters 2002), with increases in the survival and fecundity of phytophogous insects in nutrient-stressed environments being attributed to nitrogen enrichment (Landsberg 1990, Price 1991).

The loss of higher trophic groups from systems can potentially affect the community dynamics of lower trophic groups. Higher trophic levels such as predators and parasitoids seem to be more sensitive to fragmentation than do lower trophic levels (Karieva 1987, Davies et al. 2000), and small urban remnants in Sydney have been found to support a less diverse population than do large remnants (Gibb and Hochuli 2002).

Insectivorous birds are also found to be negatively affected by fragmentation events and are known to play an important role in the regulation of invertebrate herbivores; the removal of birds from systems leads to increased numbers of arthropods and levels of defoliation (Floyd 1996, Strong et al. 2000). In Australia, comparisons between small and large remnants have found that small remnants support fewer insectivorous bird species and fewer individuals (Sewell and Catterall 1998, Parsons et al. 2003). We suggest that the loss of avian predators 
Fig. 2. Total proportion chewing damage $(+\mathrm{SE})$ for small remnants, edge, and interior site treatments $(n$ $=5)$.

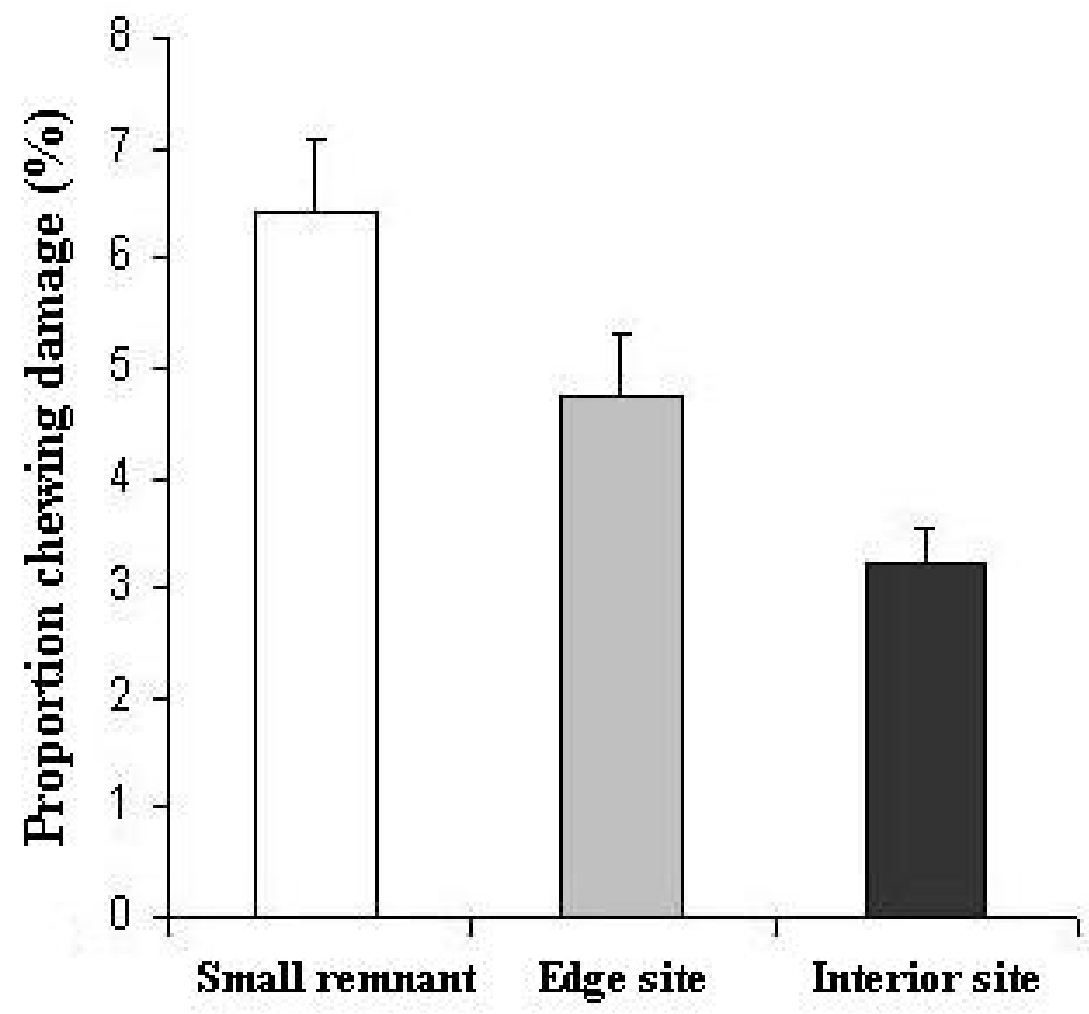

and parasitoids, whether through fragmentation per se or indirectly through increased disturbance or niche overlap with introduced and more competitive species, may ultimately lead to repeated and continued outbreaks of defoliating herbivores supporting predictions of predator release.

Finally, it is likely that the true level of leaf damage by invertebrate herbivores has been underestimated in this study, especially for sap-feeding insects, because only damage causing leaf discoloration was recorded. Furthermore, because mature, visually "healthy" trees were used rather than trees that were obviously suffering from dieback, it is probable that the true levels of damage are actually much greater than those observed.
The mechanisms driving levels of herbivory in urban remnants are complex, and it is difficult to identify one single factor as the primary force. We suggest that the urban environment is one of high stress with significant shifts in biota that increase the potential for folivorous insects. Several factors in combination, in particular nutrient enrichment and predator release, may be influencing the patterns of herbivory observed in our study. The high levels of disturbance and resulting poor-quality habitat provided by many small urban remnants create management challenges for their persistence in urbanized landscapes. Urban remnants face a diversity of threats, and managing them for competing interests such as recreation, biodiversity, and conservation means that vegetation quality is often compromised. The diversity of responses of 
invertebrates to urbanization indicates that management plans should focus on functional responses of taxa. Without a more thorough understanding of how these systems function at a large scale and how communities are affected by anthropogenic activities, their future and persistence in the landscape is significantly jeopardized.

Responses to this article can be read online at: http://www.ecologyandsociety.org/vol10/iss 1/art10/responses/

\section{Acknowledgments:}

An Australian Research Council Industry Grant through The University of Sydney and The Australian Museum funded this project. The New South Wales National Parks and Wildlife Service granted permission for fieldwork in national parks. Natasha Mooney and Glen Ciscato provided valuable field assistance. Greg Gowing and Deborah Kent provided valuable comments on the manuscript.

\section{LITERATURE CITED}

Banks, J. E. 1998. The scale of landscape fragmentation affects herbivore response to vegetation heterogeneity. Oecologia 117:239-246.

Benson, D., and J. Howell. 1990. Taken for granted: the bushland of Sydney and its suburbs. First edition. Kangaroo Press, Kenthurst, New South Wales, Australia.

Bierregaard, R. O., T. E. Lovejoy, V. Kapos, A. Augusto dos Santos, and R. W. Hutchings. 1992. The biological dynamics of tropical rainforest fragments: a prospective comparison of fragments and continuous forest. Bioscience 42:859-866.

Bolger, D. T., T. A. Scott, and J. T. Rotenberry. 1997. Breeding bird abundance in an urbanizing landscape in coastal southern California. Conservation Biology 11:406-421.

Chen, J., J. F. Franklin, and T. A. Spies. 1995. Growing-season microclimate gradients from clearcut edges into old-growth Douglas-Fir forests.
Ecological Applications 5:74-86.

Davies, K. F., and C. R. Margules. 1998. Effects of habitat fragmentation on carabid beetles: experimental evidence. Journal of Animal Ecology 67:460-471.

Davies, K. F., C. R. Margules, and J. F. Lawrence. 2000. Which traits of species predict population declines in experimental forest fragments? Ecology 81:1450-1461.

De Bruyn, L., J. Scheirs, and R. Verhagen. 2002. Nutrient stress, host plant quality and herbivore performance of a leaf mining fly on grass. Oecologia 130:594-599.

Evelegh, N. C. P., J. D. Majer, and H. F. Recher. 2001. The effects of reducing bird predation on canopy arthropods of marri (Eucalyptus calophylla) saplings on the Swan Coastal Plain, Western Australia. Journal of the Royal Society of Western Australia 84:13-21.

Fairley, A., and P. Moore. 1989. Native plants of the Sydney District: an identification guide. First edition. Kangaroo Press, Kenthurst, New South Wales, Australia.

Floyd, T. 1996. Top-down impacts on creosotebush herbivores in a spatially and temporally complex environment. Ecology 77:1544-1555.

Fox, L. R., and P. A. Morrow. 1983. Estimates of damage by herbivorous insects on Eucalyptus trees. Australian Journal of Ecology 8:139-147.

Gibb, H., and D. F. Hochuli. 2002. Habitat fragmentation in an urban environment: large and small fragments support different arthropod assemblages. Biological Conservation 106:91-100.

Golden, D. M., and T. O. Crist. 2000. Experimental effects of habitat fragmentation on rove beetles and ants: patch area or edge? Oikos 90:525-538.

Gunnarsson, B., and M. Hake. 1999. Bird predation affects canopy-living arthropods in city parks. Canadian Journal of Zoology 77:1419-1428.

Hanks, L. M., and R. F. Denno. 1993. Natural enemies and plant water relations influence the distribution of armored scale insect. Ecology 74:1081-1091. 
Karieva, P. 1987. Habitat fragmentation and the stability of predator-prey interactions. Nature 326:388-390.

King, S. A., and R. T. Buckney. 2002. Invasion of exotic plants in nutrient-enriched urban bushland. Australian Journal of Ecology 27:573-583.

Landsberg, J. 1989. A comparison of methods for assessing defoliation, tested on eucalypt trees. Australian Journal of Ecology 14:423-440.

Landsberg, J. 1990. Dieback of rural eucalypts: the effects of stress on the nutritional quality of foliage. Australian Journal of Ecology 15:97-107.

Landsberg, J., and C. Ohmart. 1989. Levels of insect defoliation in forests: patterns and concepts. Trends in Ecology and Evolution 4:96-100.

Laurance, W. F., T. E. Lovejoy, H. L. Vasconcelos, E. M. Bruna, R. K. Didham, P. C. Stouffer, C. Gascon, R. O. Bierregaard, S. G. Laurance, and E. Sampaio. 2002. Ecosystem decay of Amazonian forest fragments: a 22-year investigation. Conservation Biology 16:605-618.

Louda, S. M., and S. K. Collinge. 1992. Plant resistance to insect herbivores: a field test of the environmental stress hypothesis. Ecology 73:153-169.

Major, R. E., F. J. Christie, G. Gowing, G. Cassis, and C. A. M. Reid. 2003. The effect of habitat configuration on arboreal insects in fragmented woodlands in south-eastern Australia. Biological Conservation 113:35-48.

Marzluff, J. M., and K. Ewing. 2001. Restoration of fragmented landscapes for the conservation of birds: a general framework and specific recommendations for urbanizing landscapes. Restoration Ecology 9:280-292.

Møller, A. P. 1989. Nest site selection across fieldwoodland ecotones: the effect of nest predation. Oikos 56:240-246.

Murcia, C. 1995. Edge effects in fragmented forests: implications for conservation. Trends in Ecology and Evolution 10:58-62.

Nuckols, M. S., and E. F. Connor. 1995. Do trees in ornamental plantings receive more damage by insects than trees in natural forests? Ecological Entomology 20:253-260.

Ohmart, C. P., and P. B. Edwards. 1991. Insect herbivory of Eucalyptus. Annual Review of Entomology 36:637-657.

Parsons, H., K. French, and R. Major. The influence of remnant bushland on the composition of suburban bird assemblages in Australia. Landscape and Urban Planning 66:43-56.

Peeters, P. J. 2002. Correlations between leaf constituent levels and the densities of herbivorous insect guilds in an Australian forest. Australian Journal of Ecology 27:658-671.

Port, G. R., and J. R. Thompson. 1980. Outbreaks of insect herbivores on plants along motorways in the United Kingdom. Journal of Applied Ecology 17:649-656.

Pouyat, R. V., M. J. McDonnell, and S. T. A. Pickett. 1995. Soil characteristics of oak stands along an urban-rural land-use gradient. Journal of Environmental Quality 24:516-526.

Price, P. W. 1991. The plant vigor hypothesis and herbivore attack. Oikos 62:244-251.

Rao, M., J. Terborgh, and P. Nuñez. 2001. Increased herbivory in forest isolates: implications for plant community structure and composition. Conservation Biology 15:624-633.

Sewell, S., and C. P. Catterall.1998. Bushland modification and styles of urban development: their impacts on birds in south east Queensland. Wildlife Research 25:41-64.

Spiller, D. A., and A. A. Agrawal. 2003. Intense disturbance enhances plant susceptibility to herbivory: natural and experimental evidence. Ecology 84:890-897.

Stone, C. 2001. Reducing the impact of insect herbivory in eucalypt plantations through management of extrinsic influences on tree vigour. Australian Journal of Ecology 26:482-488.

Strong, A. M., T. W. Sherry, and R. T. Holmes. 2000. Bird predation on herbivorous insects: indirect effects on sugar maple saplings. Oecologia 125:370-379. 
Suarez, A. V., D. T. Bolger, and T. J. Case. 1998. Effects of fragmentation and invasion on native ant communities in coastal southern California. Ecology 79:2041-2056.

White, T. C. R. 1969. An index to measure weatherinduced stress of trees associated with outbreaks of psyllids in Australia. Ecology 50:905-909.

White, T. C. R. 1984. The abundance of invertebrate herbivores in relation to the availability of nitrogen in stressed food plants. Oecologia 63:90-105. 